\title{
Platelet-rich plasma for the treatment of bone defects: from pre-clinical rational to evidence in the clinical practice. A systematic review
}

\author{
Alice Roffi ${ }^{1}$ - Berardo Di Matteo ${ }^{1,2}$ • Gopal Shankar Krishnakumar ${ }^{1}$ - Elizaveta Kon ${ }^{1}$. \\ Giuseppe Filardo ${ }^{3}$
}

Received: 31 October 2016 / Accepted: 7 November 2016/Published online: 26 November 2016

(C) The Author(s) 2016. This article is published with open access at Springerlink.com

\begin{abstract}
Purpose The treatment of large bone defects represents a significant challenge for orthopaedic surgeons. In recent years, biologic agents have also been used to further improve bone healing. Among these, platelet-rich plasma (PRP) is the most exploited strategy. The aim of the present study was to systematically review the available literature to identify: 1) preclinical in-vivo results supporting the rational of PRP use for bone healing; 2) evidence from the clinical practice on the actual clinical benefit of PRP for the treatment of fractures and complications such as delayed unions and non-unions. Methods A systematic review of the literature was performed on the application of PRP in bone healing, using the following inclusion criteria: pre-clinical and clinical reports of any level of evidence, written in English language, published in the last 20 years (1996-2016), on the use of PRP to stimulate longbone defect treatment, with focus on fracture and delayed/ non-unions healing.

Results The search in the Pubmed database identified 64 articles eligible for inclusion: 45 were preclinical in-vivo studies and 19 were clinical studies. Despite the fact that the overall pre-clinical results seem to support the benefit of PRP in $91.1 \%$ of the studies, a more in depth analysis underlined a lower success rate, with a positive outcome of $84.4 \%$ in terms
\end{abstract}

Berardo Di Matteo

berardo.dimatteo@gmail.com

1 Nano-Biotechnology Laboratory, Rizzoli Orthopaedic Institute, Via di Barbiano 1/10, 40136 Bologna, Italy

2 I Orthopaedic and Traumatologic Clinic, Rizzoli Orthopaedic Institute, Via Pupilli 1, 40136 Bologna, Italy

3 Biomechanics Laboratory, Rizzoli Orthopaedic Institute, Via di Barbiano 1/10, 40136 Bologna, Italy of histological analysis, and even lower values considering radiological and biomechanical results $(75.0 \%$ and $72.7 \%$ positive outcome respectively). This was also mirrored in the clinical literature, where the real benefit of PRP use to treat fractures and non-unions is still under debate.

Conclusion Overall, the available literature presents major limitations in terms of low quality and extreme heterogeneity, which hamper the possibility to optimize PRP treatment and translate it into a real clinical benefit despite positive preclinical findings on its biological potential to favour bone healing.

Keywords Bone defect $\cdot$ Bone healing $\cdot$ Fracture $\cdot$ Growth factors $\cdot$ Non-union $\cdot$ PRP

\section{Introduction}

The treatment of large bone defects represents a significant clinical challenge for orthopaedic surgeons [1,2]. The wellorchestrated regenerative ability of bone to heal is hampered, in the case of complex defects, by the lack of a template for regeneration and, eventually, it requires surgical intervention [3]. Autografts and allografts are considered to be the major bone substitutes, however they each have their own limitations regarding availability, donor site morbidity and chronic pain, leading to not always optimal results [4]. In order to overcome these issues, several bone substitute materials have been developed and applied in the clinical practice [5, 6]. To further improve the success rates, co-adjuvant agents have also been proposed, which may enhance implant osseointegration potential and restore bone tissue function [7]. Among these, growth factors (GFs) are expressed during different phases of tissue healing and may represent a key element in promoting tissue regeneration [8]. In fact, GFs delivered through orthopaedic devices have 
been reported to enhance osteoblastic activity and favour implant integration $[9,10]$.

Platelet-rich plasma (PRP) is emerging as a powerful tool for tissue healing, thanks to the many GFs contained in platelet alpha-granules. PRP is defined as a blood derivative, where the platelets concentration is above the baseline levels, thus providing a large number of bioactive molecules in physiologic proportions [11]. Activated platelets can release more than 300 molecules that are responsible for the coordination of numerous cell-cell and cell-extracellular matrix (ECM) interactions [12]. The evidence for PRP osteogenic potential has been suggested by several in vitro studies, i.e. PRP addition in culture medium promoted the proliferation and differentiation of human mesenchymal stem cells (MSCs) [13, 14], and the effect of PRP on osteogenic differentiation was also seen on human adipose derived stem cells (ADSCs) [15]. Furthermore, PRP can improve cell chemokinesis and chemotaxis through cytoskeleton reorganization and accelerate cell migration, thus influencing osteoblast like cells mobility [16]. Finally, anti-microbial effects have been suggested $[17,18]$, which are highly desirable in relation to a surgical bone application. However, besides the beneficial role in terms of proliferation and differentiation, as well as cell migration and protection towards microbial contamination, in-vitro studies have also shown controversial results on PRP potential to favour bone healing [19-21].

Thus, the aim of this study was to systematically review the available literature to identify both preclinical in-vivo results supporting the rational of PRP use for bone healing, and the evidence from the orthopaedics practice on the actual clinical benefit of PRP for the treatment of bone disorders.

\section{Materials and methods}

A systematic review of the literature was performed on the use of PRP in both pre-clinical in-vivo setting and clinical setting for the treatment of fractures and delayed unions/non-unions. The search was conducted on the PubMed database on August 1st, 2016 using the following string: (PRP OR platelet-rich plasma OR plasma rich in growth factors OR platelet derived growth factor OR platelet derived OR platelet gel OR platelet concentrate OR PRF OR platelet rich fibrin OR platelet rich membrane OR ACP OR autologous conditioned plasma OR PRGF OR platelet lysate) AND (fracture OR trauma OR traumatic OR non union OR mal union OR post-traumatic OR pseudoarthrosis OR delayed union OR bone defect).

The screening process and analysis were conducted separately by two independent observers (BDM and GS). First, the articles were screened by title and abstract, using the following inclusion criteria: pre-clinical and clinical reports of any level of evidence, written in English language, published in the last 20 years (19962016), on the use of PRP to stimulate long-bone defect treatment, with focus on fracture and delayed/non-unions healing.
Exclusion criteria were articles written in other languages, reviews, case reports or case series with less than ten patients included, or studies analysing other applications of PRP in bone pathology. In the second step, the full texts of the selected articles were screened, with further exclusions according to the previously described criteria. Reference lists from the selected papers were also screened. A flowchart of the systematic review process is provided in Fig. 1. Relevant data were then extracted and collected, with the consensus of the two observers, in a database including pertinent information (type of study, number of cases, follow-up, PRP preparation, cytology and application modality, type of surgical treatment or animal model used, type of bone or other materials applied, type of evaluation and results) to be analysed for the purposes of the present manuscript.

\section{Results}

In total 3160 articles were screened and 64 articles were found to be eligible for inclusion in the present review. Among these, 45 were pre-clinical in-vivo studies [1, 2, 4, 22-63] and 19 were clinical studies [64-83] (Fig. 1). The trend of publication of pre-clinical and clinical trials over years has been reported in Fig. 2. Results will be discussed separately for pre-clinical and clinical studies.

\section{Pre-clinical studies}

\section{Animal models}

Of the 45 identified studies (Table 1), 20 (44.4\%) used a rabbit model, while other animals were used in a smaller number of studies, i.e. rat in eight studies $(17.8 \%)$, sheep in seven studies $(15.6 \%)$, dog in four studies $(8.9 \%)$, pig in four studies $(8.9 \%)$ and goat in two studies $(4.4 \%)$. With regard to defect type, bone sites were tibia in 16 studies $(35.6 \%$ ) (four segmental, 14 cylindrical defects), femur in 14 studies (31.1\%) (two segmental, eight cylindrical defects, four fractures), radius in ten studies $(22.2 \%$ ) (nine segmental, one fracture), fibula in 1 study $(2.2 \%$ ) (one fracture), ulna in three studies $(6.7 \%)$ (three segmental defects) and metatarsus in one study $(2.2 \%)$ (one segmental defects).

With regard to the delivery mode, 3/45 studies delivered PRP through percutaneous injection while the remaining studies used the surgical approach to apply PRP either alone or in combination with other materials. Only one paper described the combination of percutaneous PRP injection and surgical PRP delivery with biomaterial. Besides seven articles (16\%) documenting the effect of PRP alone, most of the studies (38 papers, $84 \%$ ) analysed the effect of PRP with other materials: 20 studies $(53 \%)$ reported the use of three dimensional scaffolds, nine $(23.5 \%)$ with auto $(n=5) /$ allo $(n=3) /$ xenografts $(n=1)$ and nine $(23.5 \%)$ with powders/granules/pastes. 
Fig. 1 PRISMA flowchart of the papers' selection process
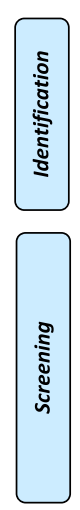

Additional records identified through references $(n=7)$
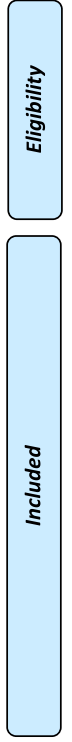

Records identified through

PubMed searching

$(n=3160)$

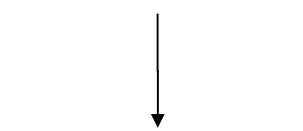

Abstracts screened $(n=166)$

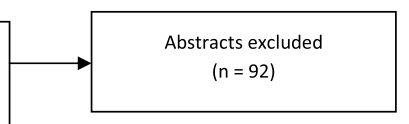

Full-text articles excluded $(n=18)$

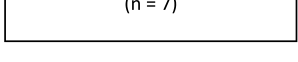

Pre-clinical article included in qualitative assessment

$$
n=45:
$$

20 dealing with PRP with scaffold 9 dealing with PRP with Autograft/Allograft/Xenograft

9 dealing with PRP with Powder/Granules

7 dealing with PRP alone

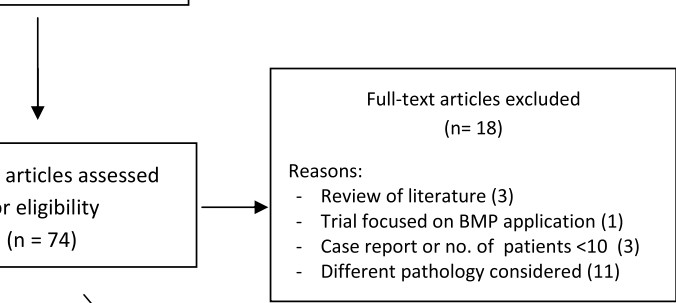

Finally, with regard to other biological augmentations, 11 papers $(24.4 \%)$ reported the use of MSCs as a co-adjuvant osteogenic factor in their studies. BMSCs was the favourite cell source, used in eight papers, followed by bone marrow concentrate (BMC) in two articles, and BMSCs vs. ADSCs were reported in one article.

\section{PRP preparation}

Platelet count was reported in studies 32/45 (71\%) with heterogeneous platelet concentration. However, all showed significantly higher levels of platelets than in whole peripheral blood, ranging from $1.1 \mathrm{x}$ to $10.1 \mathrm{x}$. Sixteen out of 45 papers
Fig. 2 Pre-clinical and clinical studies published over time

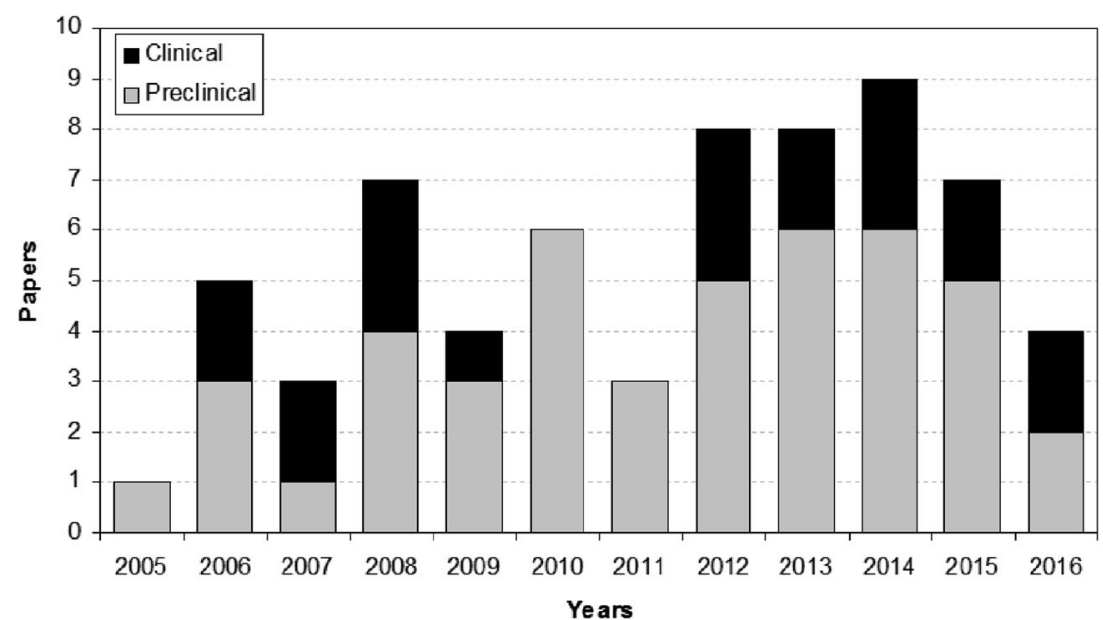




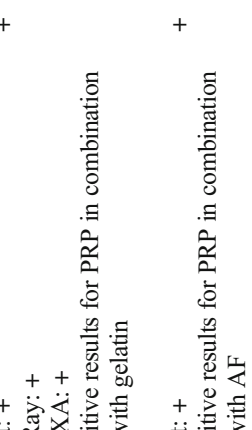

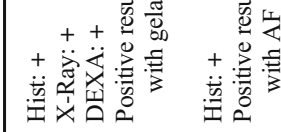

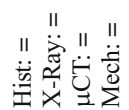

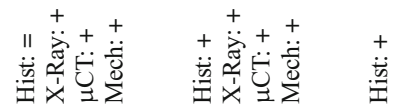

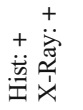

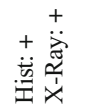

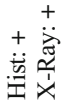

\begin{tabular}{|c|}
\hline 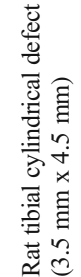 \\
\hline
\end{tabular}

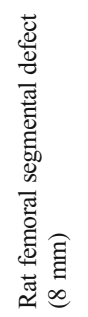

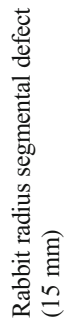

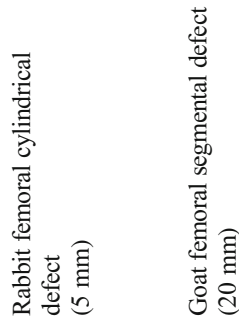

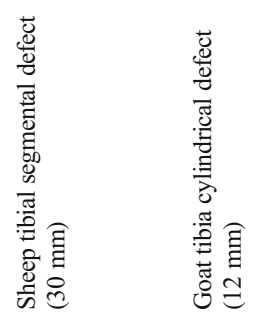

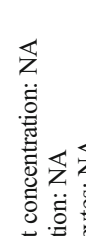
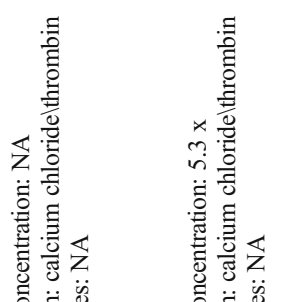

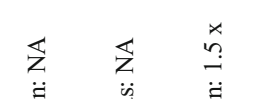

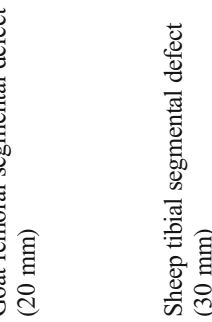

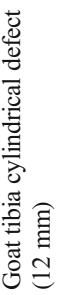

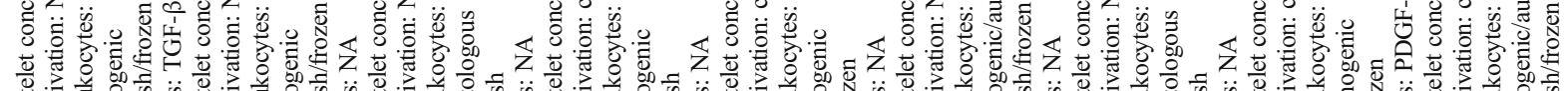

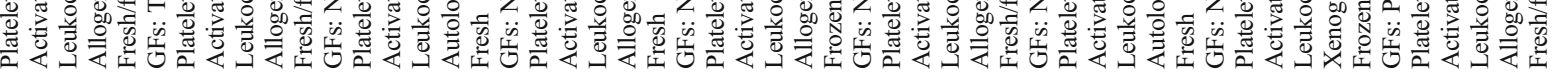

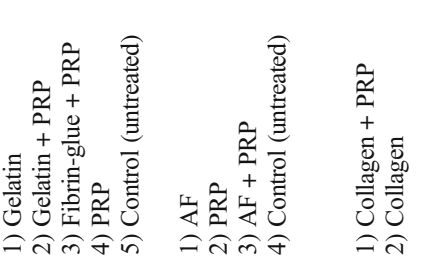

$\sum_{i}^{n}$

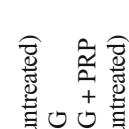

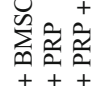

䒠说基

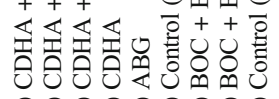

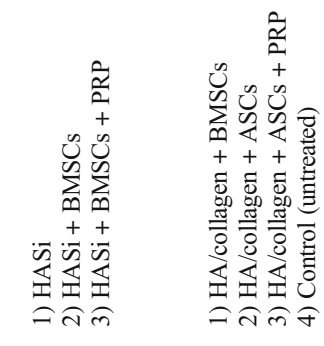

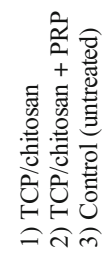

突

तิ

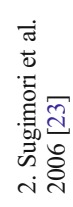

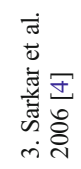

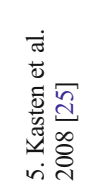

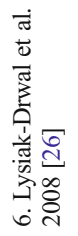

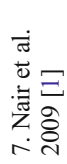

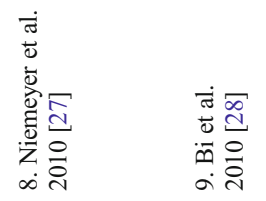




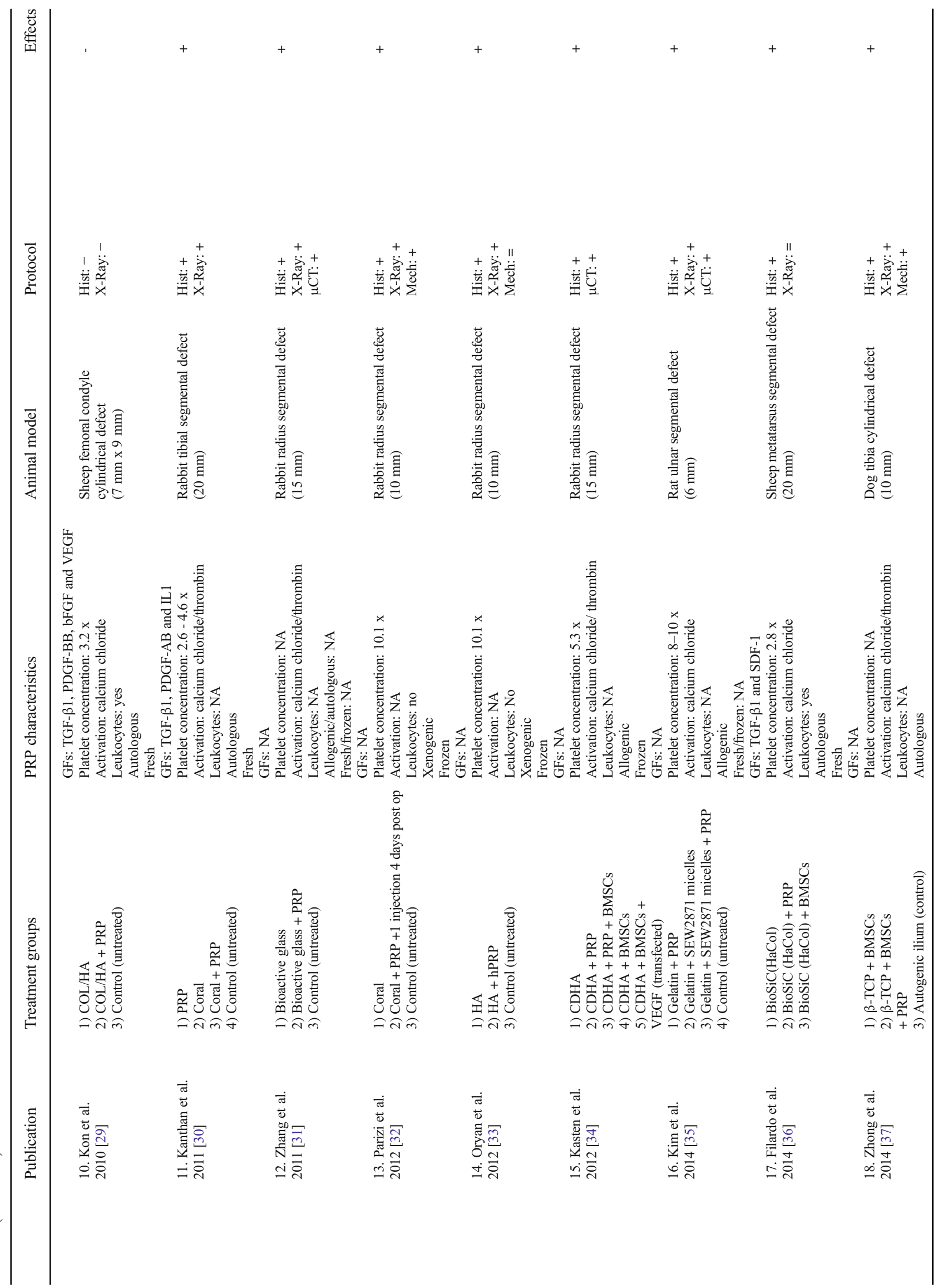




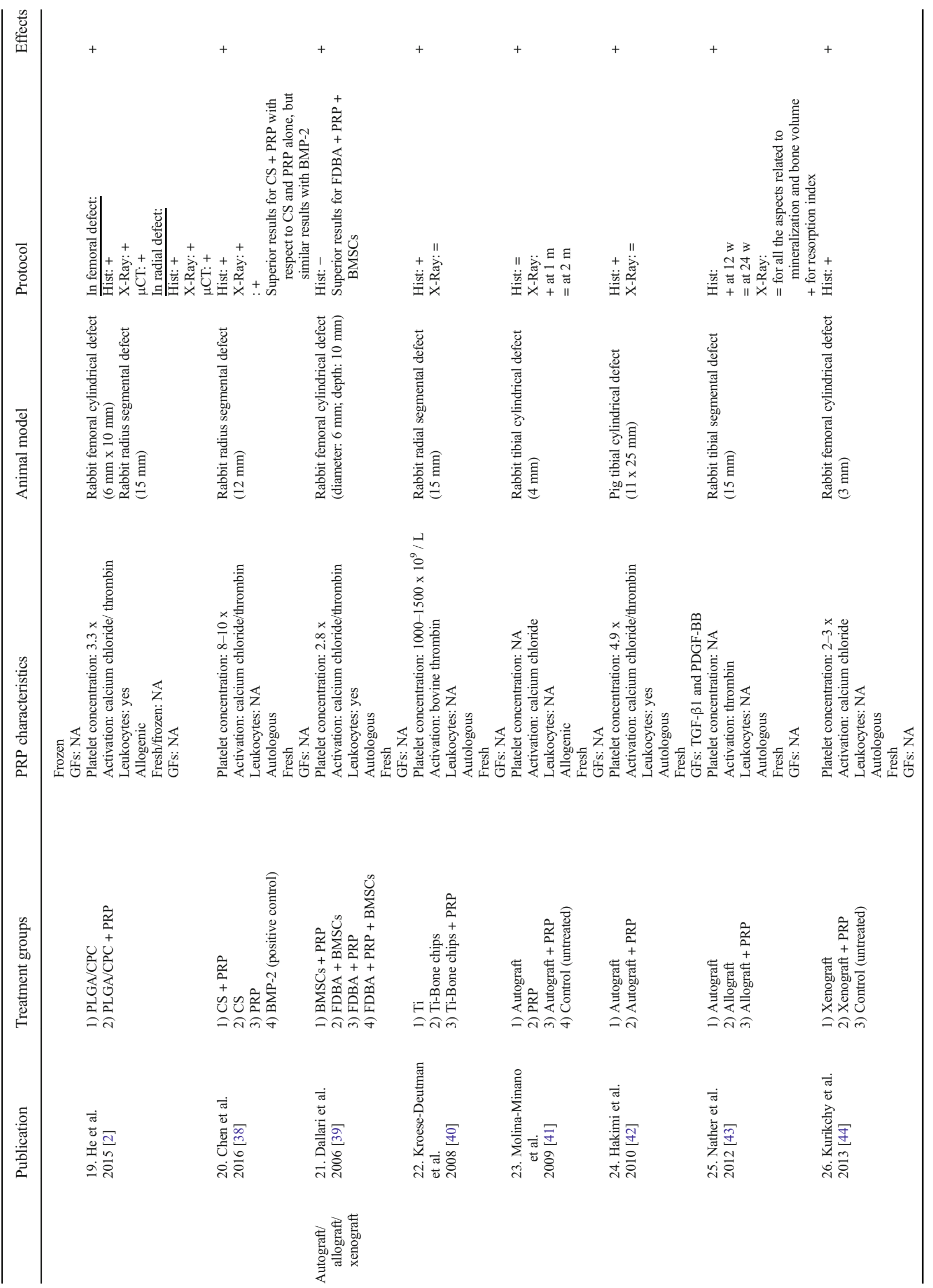




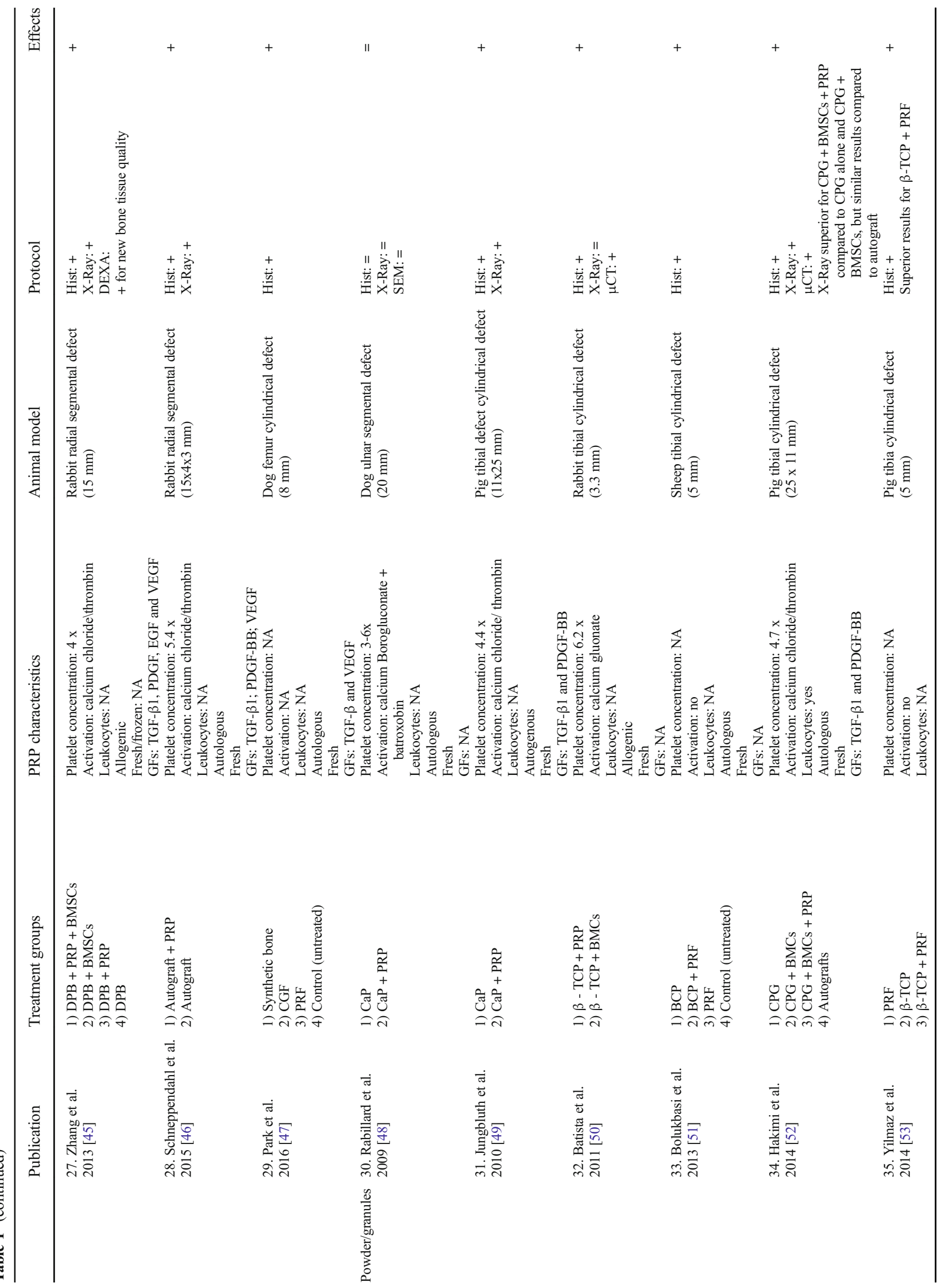




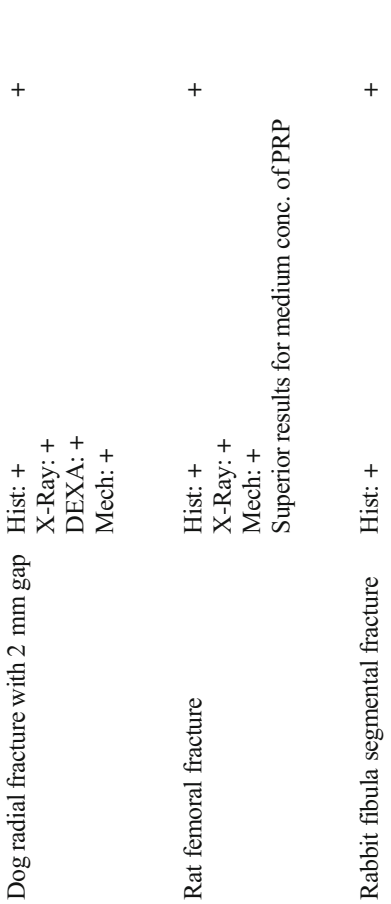

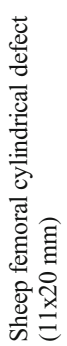

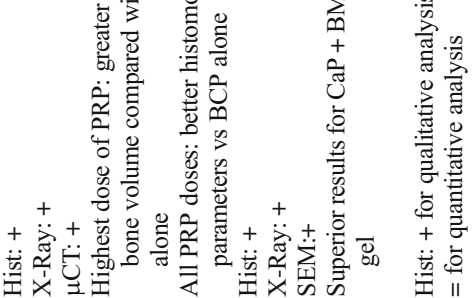

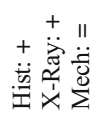

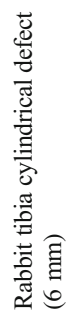

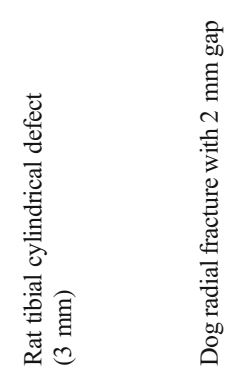

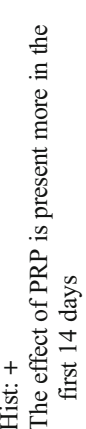

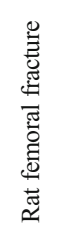

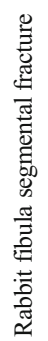
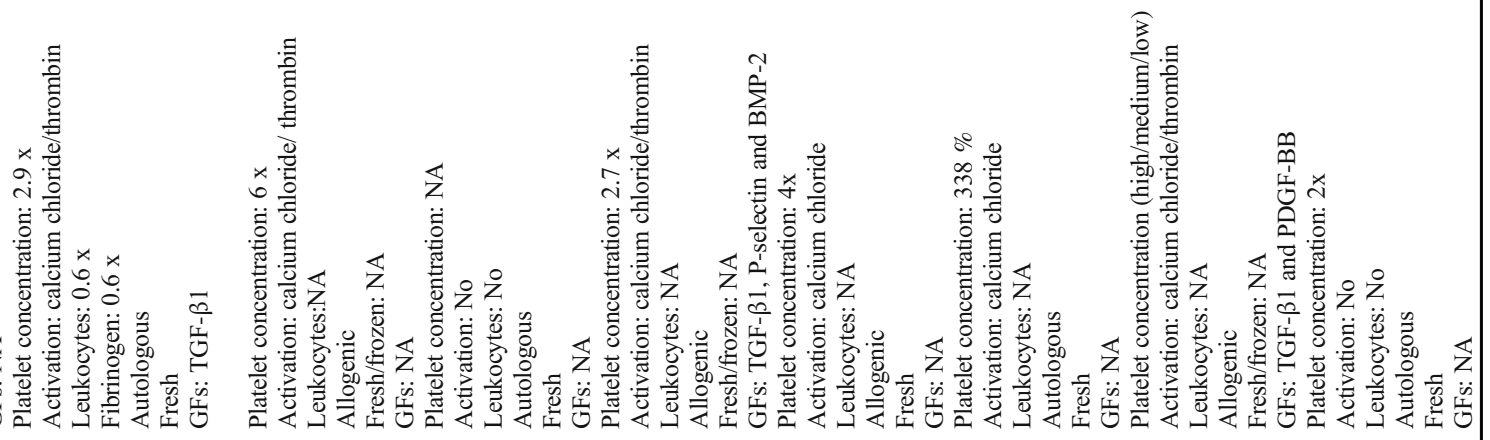

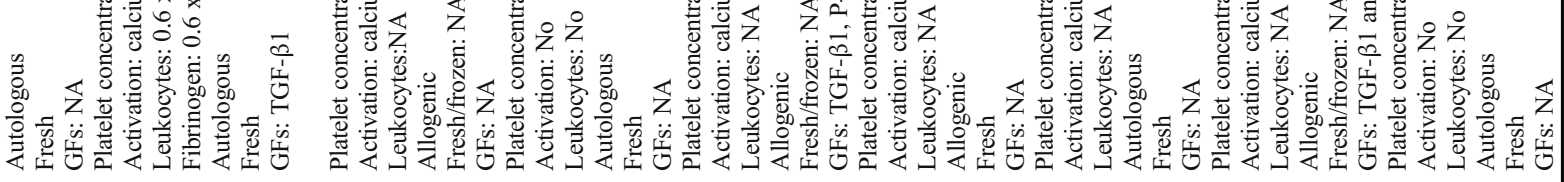
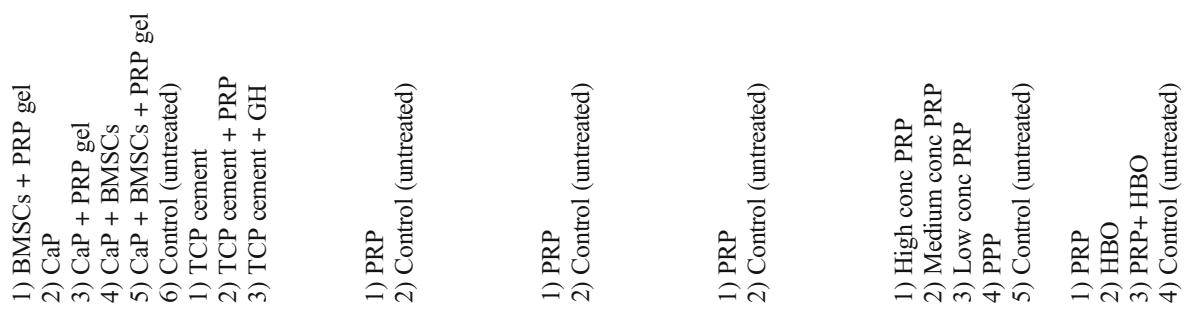

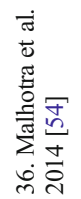

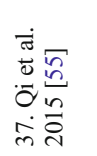
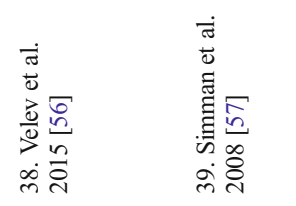

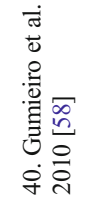

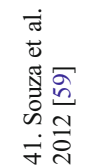

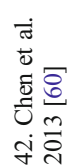

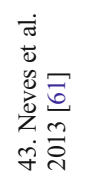

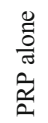




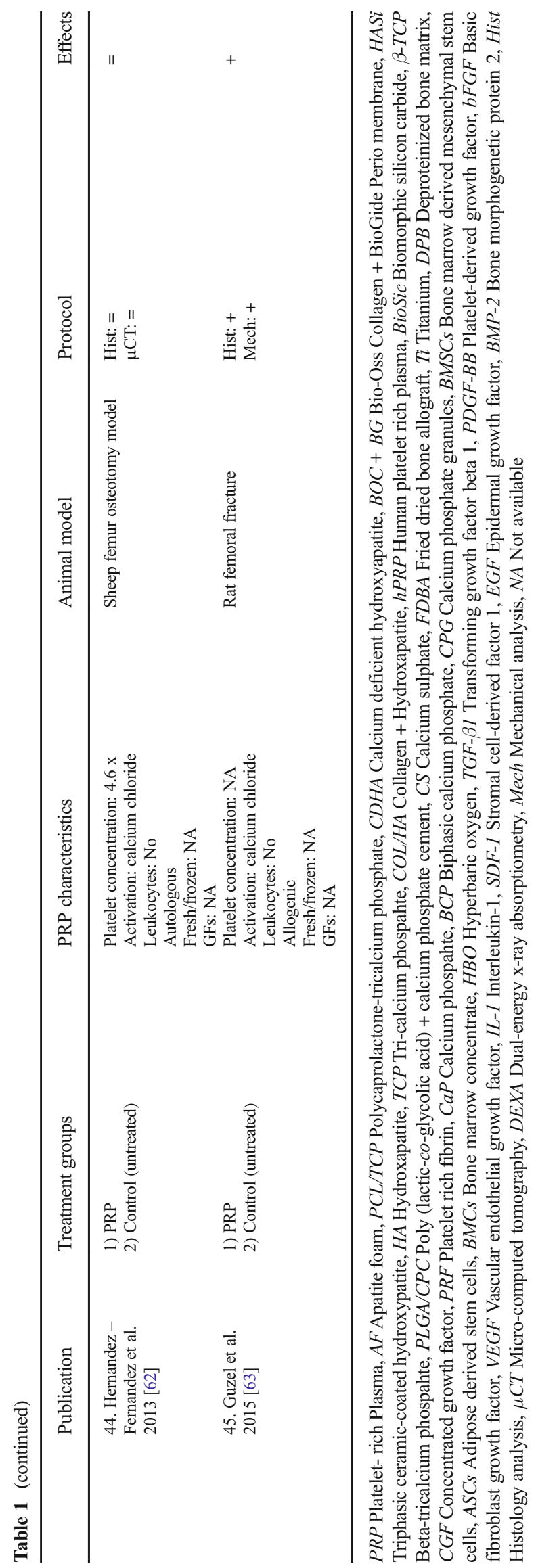

reported information about leukocytes content in PRP, nine of which described the use of leukocyte-rich PRP and seven of leukocyte-poor PRP. Only one paper out of 45 reported fibrinogen content. Fourteen studies analysed PRP for GFs, which included TGF- $\beta 1$ (in 14), PDGF (in ten), VEGF (in four), bFGF (in one), SDF-1 (in one), p-selectine (in one), BMP-2 (in one), IL-1 (in one) and EGF (in one).

Thirty-two out of 45 papers $(71 \%)$ reported information about the use of fresh or frozen PRP: 26 were fresh and six frozen; while $42(93.3 \%)$ papers reported the type of PRP in terms of autologous (in 24), allogeneic (in 15), and xenogeneic (in three) origin. Finally, PRP activation modality was not reported in 12 studies; among studies where this was specified (33 papers, $73.3 \%), 20(60.6 \%)$ reported a combination of $\mathrm{CaCl}_{2}$ and thrombin, nine $(27.3 \%)$ used $\mathrm{CaCl}_{2}$ alone, two $(6.1 \%)$ thrombin alone, one $(3 \%)$ calcium gluconate, one (3\%) calcium borogluconate and one (3\%) batroxobin.

\section{Pre-clinical findings}

Overall positive results were shown in 41 studies (91\%), while three studies $(7 \%)$ showed the same results as control and one study (2\%) showed negative effects of PRP use. In particular, among the 20 studies reporting the use of PRP with scaffolds (hydroxyapatite alone or in combination with collagen was the most frequent material used), 18 showed positive results; among the nine papers using bone grafts, all reported good results. Among the nine studies on PRP with powder/ granules, eight showed a good outcome. Finally, among the seven studies where PRP was used alone, six reported good results while one study using PRP injections failed to show significant effects. Finally, the use of MSCs always provided a benefit, with PRP further increasing the outcome in all 11 studies.

Further analyses have been performed according to the results of each specific evaluation performed. The histological outcome has been reported in 45 papers, with $38(84.4 \%)$ showing significant improvement in bone healing. The radiographic outcome was reported in 32/45 papers; among these studies $24(75.0 \%)$ showed significant bone consolidation. The micro-computed tomography (CT) outcome was reported in 11 papers and significant bone area formation was reported in nine $(81.8 \%)$ studies. DEXA analysis was reported only in three studies, with good results in favour of PRP in all papers. Finally, biomechanical tests in regard to torsion, torque and bone strength, were performed in ten papers and seven $(70 \%)$ of these studies documented significantly better biomechanical properties.

\section{Clinical studies}

A total of 19 clinical trials were found to be eligible for inclusion in the present review: nine dealt with fracture 
management [64-72] whereas ten focused on fracture complications [73-83] (i.e. delayed unions or non-unions; Table 2).

\section{Treatment of fractures}

Eight out of nine studies were RCTs and one was a retrospective comparative trial [64]. Three studies aimed at understanding the role of PRP in stimulating healing after iatrogenic fractures: two trials in opening-wedge high tibial osteotomy (HTO) $[65,66]$ and one in tibial distraction osteogenesis for limb lengthening [67]. The other six trials focused on disparate traumatic injuries: two papers on hip fractures [68, 69], one paper on calcaneus fractures [70], one (the retrospective comparative trial) on complex bimalleolar fractures [64], one on tibial pilon fractures [71] and one on intra-articular distal radial fractures [72]. With regard to the application strategies, PRP was locally applied during surgery in eight studies, whereas in one case a delayed PRP injection was applied (3-6 weeks after primary surgery) [70]. PRP was leukocyterich in five papers and leukocyte-depleted in two studies, while in two papers authors did not provide specific details about the PRP formulation adopted. In six trials PRP was associated to other "augmentation strategies", such as MSCs and/or bone graft (Table 2).

Overall, eight out of nine papers reported radiologic outcomes: six of them revealed better results with PRP, one found no difference, whereas one paper documented worse radiologic results with the biologic augmentation. Clinical outcomes were reported in only five papers, i.e. functional subjective scores and/or objective measurements and/or complications after PRP treatment: in three cases PRP did not provide any beneficial contribution, whereas in the remaining two studies it contributed to a superior clinical outcome. Finally, only one trial documented histomorphometric results, showing that the addition of PRP to bone chips, even more if combined with $\mathrm{BMC}$ augmentation, was able to promote a superior healing of the high tibial osteotomy gap site (Table 2).

\section{Treatment of delayed unions/non unions}

Out of the ten studies (11 papers in total) on the application of PRP to manage delayed unions or non-unions [73-83], four used a minimally invasive approach through percutaneous PRP injections, six studies used PRP as topical enhancer during revision surgery, whereas one study reported results of both treatment approaches (Table 2). Only one trial (which was the object of two different publications, one reporting the preliminary results and the other reporting the complete data) was a RCT [73, 74], whereas all the others were case series. In four studies PRP was used together with other augmentation strategies (bone graft or synthetic bone). PRP was leukocyte-rich in two studies and leukocyte-depleted in three studies, while in five trials authors did not provide specific details about the PRP formulation adopted (Table 2).

All but one [75] study considered patients affected by delayed union/non-union in different anatomical districts pooled together (mainly humerus, femur and tibia, which are the most common sites for this kind of complication), thus reducing the homogeneity of the cohorts of patients. With regard to the outcome, two case series (where PRP was injected at the site of non-union or delayed union) failed to documented a beneficial effect of the biological stimulation [76, 77]. The other reports suggested instead a positive role of PRP, although the only RCT documented a clear advantage of bone morphogeneic protein 7 (BMP-7) over PRP in stimulating bone healing (Table 2) [73, 74].

\section{Discussion}

This systematic research of the literature documented a growing interest on PRP use for bone disorders, with an increasing number of papers published over time which show a complex scenery and more controversial results than previously thought.

In fact, while basic science suggests several favourable potential effects of PRP for bone healing, and platelet concentrates have also been successfully used in other medical fields to enhance bone and soft tissue regeneration [5, 84-86], the evidence on its real benefit is questionable. The first phase of the literature analysis focused on preclinical in-vivo evidence, which should allow us to understand potential and indications for PRP use. This systematic review documented 45 papers reporting heterogeneous models both in terms of animal model and defect type chosen. This is an important factor to consider in terms of results transferability to the clinical field. In fact, although several models are appropriate for the evaluation of bone regeneration, not all of them closely reproduce human tissue characteristics. Chosen models should present physiological and pathophysiological analogies to favour results transferability: for this reason larger models more closely resemble the human condition [87]. For example, pig models present bone features similar to humans in terms of mineral density, concentration and healing capacity, with a 1.2 to $1.5 \mathrm{~mm}$ per day growth rate, similar to bone regeneration capacity in humans [88]. Among the studies found in this systematic review, only four chose the pig model, while the majority adopted smaller models with rabbits or even rats. Moreover, these animal models analysed surgically-created acute lesions which were treated immediately, oppositely to what happens in the clinical practice. Despite the inherent limits of these models in terms of transferability to humans, these studies still showed overall promising findings, with a positive outcome documented in $91.1 \%$ of the papers. However, a more in depth analysis shed some doubts on the 


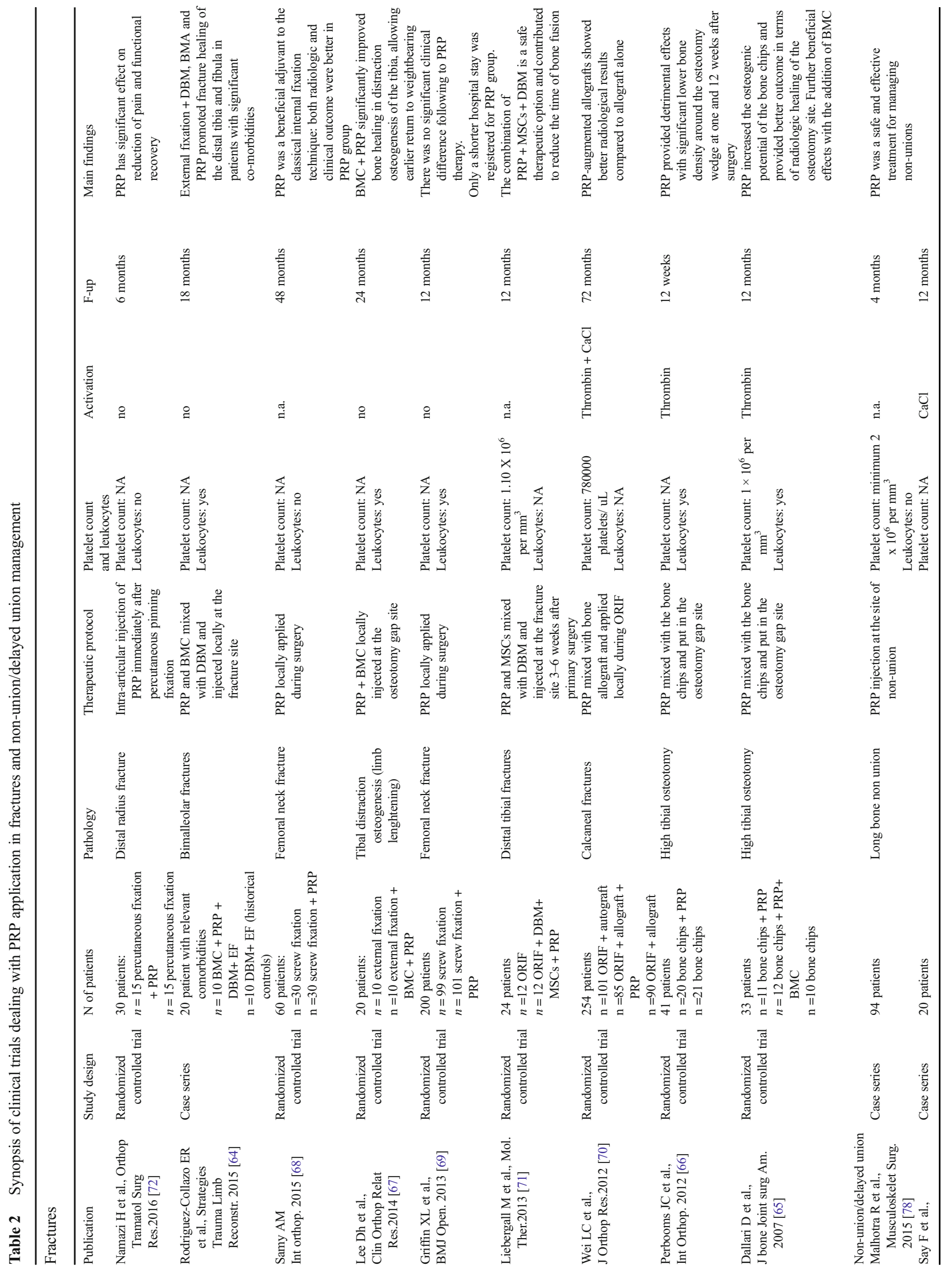




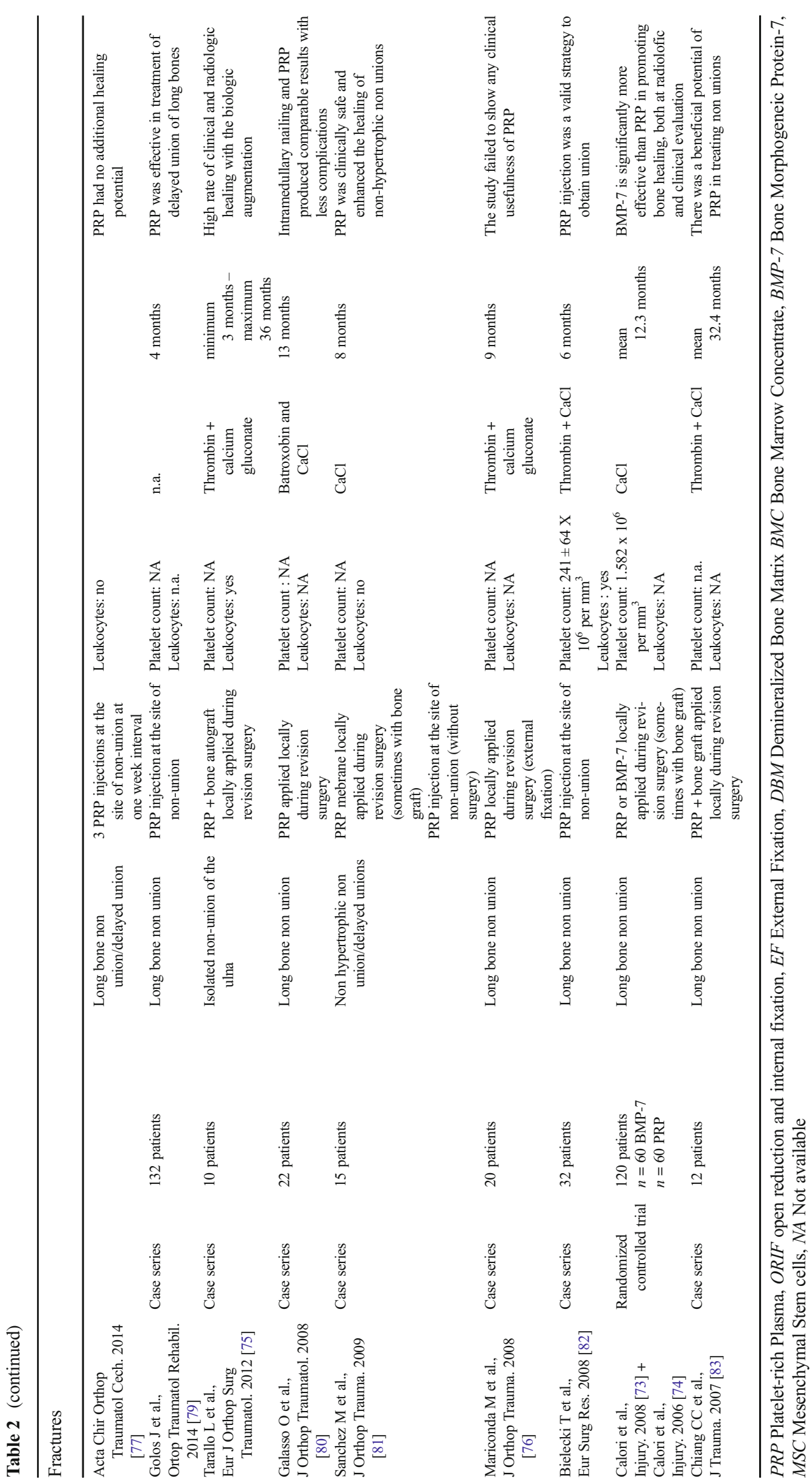


real potential of PRP. In fact, looking at the specific evaluations performed, the percentage of success decreased. While histological analysis showed an improvement in $84.4 \%$ of the experiments, imaging analysis showed a lower success, with a $75.0 \%$ success rate documented through radiological analysis. Moreover, the higher quality of the regenerated tissue should lead to a stronger tissue, but biomechanical analysis could prove superior results related to PRP use only in $72.7 \%$ of the studies. This is an important factor, because it raises some caution on the interpretation of the positive results of several studies based on different and more successful outcomes. An improved regeneration should allow for higher biomechanical properties to be considered significant, otherwise the real usefulness of this biological augmentation remains questionable. Besides the lack of biomechanical evaluations, performed only in a minority of preclinical studies, other aspects hinder the understanding of PRP potential. These lie in the limitations of the current preclinical literature, in terms of extreme heterogeneity of the published studies as well as often poor study quality.

Most of the studies fail to report key aspects that may influence the final outcome and hinder a correct interpretation of the results: platelet concentrations, leukocyte components, activation modality etc. are often overlooked. Even though several products with a wide range of cell concentration are included in the PRP family [89], the number and type of cells applied is not a secondary aspect. A platelet concentration of approximately $(1,000,000 / \mu \mathrm{l})$ has been linked to positive biological effects in bone regeneration by Weibrich et al. [90]. Chen et al. [60] showed how a medium concentration of PRP $\left(2.65 \pm 0.2 \times 10^{9} / \mathrm{ml}\right)$ induced osteogenic differentiation of BMSCs and improved fracture healing, while a high concentration of PRP $\left(8.21 \pm 0.4 \times 10^{9} / \mathrm{ml}\right)$ inhibited osteogenic differentiation of BMSCs and delayed callus remodelling in a rat femoral osteotomy. Other than the importance of platelet number, Perut et al. [21] underlined the contribution of other cells to the overall effect: leukocyte-rich PRP induced significantly higher proliferation of BMSCs compared to leukocytedepleted PRP. Moreover, other studies emphasized the importance of further aspects related to PRP, such as storage or activation modality that, together with the autologous or allogeneic nature, the characteristics of the donor and the preparation method etc., may influence the molecules released and the biological results of platelet concentrates [88, 91, 92]. PRP effects may also depend on the treatment condition, i.e. the application modality, in particular in terms of injective or surgical delivery (a more solid state with more fibrin may imply a different release of the GFs from the fibrin net [93]), and even more with combined augmentation procedures. Preclinical studies are highly heterogeneous in terms of materials combined with PRP, which has been suggested to influence cellsignalling molecules that promote osteogenesis [20] and, in the end, the success rate [5]. Moreover, PRP has also been combined with MSCs: while overall results of the combined treatment seemed positive, the independent contribution of PRP remains questionable.

All these factors contribute to the complexity of the preclinical findings and leave many open questions on the optimization and transferability of PRP potential for humans use. Overall clinical findings confirm the preclinical scenery. The lack of clear indications on the best way to apply platelet concentrates is reflected by an extreme heterogeneity in terms of PRP preparations, as well as in targets and delivery methods. Moreover, the quality of the studies is limited: as for the preclinical field, many key parameters are omitted, the study design is poor and even for randomized trial low patients numbers and the presence of concomitant confounding factors hinder the possibility to have clear results. This is a key aspect since a tendency to report better results with lower quality studies compared to more scientific robust ones has already been reported [5]. Finally, it has to also be emphasized for clinical studies that not all positive results may be clinically significant. In fact, the rational of a biological augmentation is to favour a faster recovery. Earlier weight bearing and mobilization may lead to fewer adhesions, higher postoperative range of motion and earlier return to physical activity [88]. To this aim, positive histological or imaging findings may be insufficient if not coupled by a significant increase in biomechanical quality of bone. The analysis of the clinical studies in terms of documented clinical benefit shows an even lower outcome than what is suggested by imaging findings, which further questions the real benefit provided by PRP use to favour bone regeneration in the clinical practice.

Thus, while positive findings have been suggested by the pre-clinical literature, a more in depth evaluation shed some doubts on the real role of PRP, which are confirmed by the limited benefits documented in the human experience. Currently, there is no evidence to support the routine use of PRP to enhance bone healing. Therefore, until trials with high methodological quality will allow the optimization of its biological potential and clearly prove results and indications, PRP use should be restricted to controlled studies investigating its real benefit for the treatment of bone pathologies.

\section{Conclusions}

This systematic research of the literature documented a growing interest on PRP use for bone disorders. While the overall pre-clinical results seem to support the benefit of PRP in $91.1 \%$ of the studies, a more in depth analysis underlines a lower success rate, with a positive outcome of $84.4 \%$ in terms of histological analysis, and even lower when considering radiological and biomechanical analysis, $75.0 \%$ and $72.7 \%$, respectively. This is reflected by controversial findings also documented in the clinical literature, where the real 
benefit of PRP use to treat fractures and non-unions is questionable. Overall, the available literature presents major limitations in terms of low quality and extreme heterogeneity, which hamper the possibility to optimize PRP treatment and translate positive preclinical findings on its biological potential to favour bone healing into a real clinical benefit.

Acknowledgment This work was partially supported by European Union Seventh Framework Programme FP7- PEOPLE-2013-ITN under Grant Agreement no. 607051-Bioinspire: Training program on new bioinspired bone regeneration.

\section{Compliance with ethical standards}

\section{Conflict of interest Elizaveta Kon}

Zimmer-Biomet (USA): Paid presenter or speaker

Cartiheal (Israel): Paid consultant; Stock or stock options

Fidia (Italy): Paid presenter or speaker

Finceramica (Italy): Paid presenter or speaker

International Cartilage Repair Society: Board or committee member

Journal of Experimental Orthopedics: Editorial or governing board

Giuseppe Filardo

Zimmer-Biomet (USA): Institutional Support

Cartiheal (Israel): Consultant and Institutional Support

Fidia (Italy): Consultant and Institutional Support

Finceramica (Italy): Consultant and Institutional Support

Green Bone (Italy): Consultant and Institutional Support

DSM Biomedical (USA): Institutional Support

IGEA Clinical Biophisic: Institutional Support

PIRAMAL/ Smith-Nephew: Institutional Support

All the other authors declare that there are no competing interests regarding the publication of this paper.

Open Access This article is distributed under the terms of the Creative Commons Attribution 4.0 International License (http:// creativecommons.org/licenses/by/4.0/), which permits unrestricted use, distribution, and reproduction in any medium, provided you give appropriate credit to the original author(s) and the source, provide a link to the Creative Commons license, and indicate if changes were made.

\section{References}

1. Nair MB, Varma HK, Menon KV, Shenoy SJ, John A (2009) Reconstruction of goat femur segmental defects using triphasic ceramic-coated hydroxyapatite in combination with autologous cells and platelet-rich plasma. Acta Biomater 5(5):1742-1755

2. He F, Chen Y, Li J, Lin B, Ouyang Y, Yu B, Xia Y, Yu B, Ye J (2015) Improving bone repair of femoral and radial defects in rabbit by incorporating PRP into PLGA/CPC composite scaffold with unidirectional pore structure. J Biomed Mater Res A 103(4): 1312-1324

3. Stevens MM (2008) Biomaterials for bone tissue engineering. Mater Today 11(5):18-25

4. Sarkar MR, Augat P, Shefelbine SJ, Schorlemmer S, Huber-Lang M, Claes L, Kinzl L, Ignatius A (2006) Bone formation in a long bone defect model using a platelet-rich plasma-loaded collagen scaffold. Biomaterials 27(9):1817-1823
5. Roffi A, Filardo G, Kon E, Marcacci M (2013) Does PRP enhance bone integration with grafts, graft substitutes, or implants? A systematic review. BMC Musculoskelet Disord 14:330

6. Gazdag AR, Lane JM, Glaser D, Forster RA (1995) Alternatives to autogenous bone graft: efficacy and indications. J Am Acad Orthop Surg 3(1):1-8

7. Wang W, Ouyang Y, Poh CK (2011) Orthopaedic implant technology: biomaterials from past to future. Ann Acad Med Singapore 40(5):237-244

8. Lieberman JR, Daluiski A, Einhorn TA (2002) The role of growth factors in the repair of bone. Biology and clinical applications. J Bone Joint Surg Am 84-A(6):1032-1044

9. Hakimi M, Grassmann JP, Betsch M, Schneppendahl J, Gehrmann S, Hakimi AR, Kröpil P, Sager M, Herten M, Wild M, Windolf J, Jungbluth P (2014) The composite of bone marrow concentrate and PRP as an alternative to autologous bone grafting. PLoS One 9(6), e100143

10. Brownlow HC, Simpson AH (2000) Metabolic activity of a new atrophic nonunion model in rabbits. J Orthop Res 18(3):438-442

11. Di Matteo B, Filardo G, Kon E, Marcacci M (2015) Platelet-rich plasma: evidence for the treatment of patellar and Achilles tendinopathy-a systematic review. Musculoskelet Surg 99(1):1-9

12. Rodriguez IA, Growney Kalaf EA, Bowlin GL, Sell SA (2014) Platelet-rich plasma in bone regeneration: engineering the delivery for improved clinical efficacy. Biomed Res Int. doi:10.1155/2014 1392398

13. Kasten P, Vogel J, Luginbühl R, Niemeyer P, Weiss S, Schneider S, Kramer M, Leo A, Richter W (2006) Influence of platelet-rich plasma on osteogenic differentiation of mesenchymal stem cells and ectopic bone formation in calcium phosphate ceramics. Cells Tissues Organs 183(2):68-79

14. El Backly RM, Zaky SH, Muraglia A, Tonachini L, Brun F, Canciani B, Chiapale D, Santolini F, Cancedda R, Mastrogiacomo M (2013) A platelet-rich plasma-based membrane as a periosteal substitute with enhanced osteogenic and angiogenic properties: a new concept for bone repair. Tissue Eng Part A 19(12):152-165

15. McLaughlin M, Gagnet $P$, Cunningham E, Yeager R, D'Amico M, Guski K, Scarpone M, Kuebler D (2016) Allogeneic platelet releasate preparations derived via a novel rapid thrombin activationp process promote rapid growth and increased BMP-2 and BMP-4 expression in human adipose-derived stem cells. Stem Cells Int. doi:10.1155/2016/7183734

16. Casati L, Celotti F, Negri-Cesi P, Sacchi MC, Castano P, Colciago A (2014) Platelet derived growth factor (PDGF) contained in platelet rich plasma (PRP) stimulates migration of osteoblasts by reorganizing actin cytoskeleton. Cell Adh Migr 8(6):595-602

17. Mariani E, Filardo G, Canella V, Berlingeri A, Bielli A, Cattini L, Landini MP, Kon E, Marcacci M, Facchini A (2014) Platelet-rich plasma affects bacterial growth in vitro. Cytotherapy 16(9):1294 1304

18. Mariani E, Canella V, Berlingeri A, Bielli A, Cattini L, Landini MP, Kon E, Marcacci M, Di Matteo B, Filardo G (2015) Leukocyte presence does not increase microbicidal activity of platelet-rich plasma in vitro. BMC Microbiol 15:149

19. Arpornmaeklong P, Kochel M, Depprich R, Kübler NR, Würzler KK (2004) Influence of platelet-rich plasma (PRP) on osteogenic differentiation of rat bone marrow stromal cells. An in vitro study. Int J Oral Maxillofac Surg 33(1):60-70

20. Mooren RE, Hendriks EJ, van den Beucken JJ, Merkx MA, Meijer GJ, Jansen JA, Stoelinga PJ (2010) The effect of platelet-rich plasma in vitro on primary cells: rat osteoblast-like cells and human endothelial cells. Tissue Eng Part A 16(10):3159-3172

21. Perut F, Filardo G, Mariani E, Cenacchi A, Pratelli L, Devescovi V, Kon E, Marcacci M, Facchini A, Baldini N, Granchi D (2013) Preparation method and growth factor content of platelet 
concentrate influence the osteogenic differentiation of bone marrow stromal cells. Cytotherapy 15(7):830-839

22. Hokugo A, Sawada Y, Hokugo R et al (2007) Controlled release of platelet growth factors enhances bone regeneration at rabbit calvaria. Oral Surg, Oral Med, Oral Pathol, Oral Radiol Endod 104(1):44-48

23. Sugimori E, Shintani S, Ishikawa K, Hamakawa H (2006) Effects of apatite foam combined with platelet-rich plasma on regeneration of bone defects. Dent Mater J 25(3):591-596

24. Rai B, Oest ME, Dupont KM, Ho KH, Teoh SH, Guldberg RE (2007) Combination of platelet-rich plasma with polycaprolactone-tricalcium phosphate scaffolds for segmental bone defect repair. J Biomed Mater Res A 81(4):888-899

25. Kasten P, Vogel J, Geiger F, Niemeyer P, Luginbühl R, Szalay K (2008) The effect of platelet-rich plasma on healing in critical-size long-bone defects. Biomaterials 29(29):3983-3992

26. Lysiak-Drwal K, Dominiak M, Solski L, Zywicka B, Pielka S, Konopka T, Gerber H (2008) Early histological evaluation of bone defect healing with and without guided bone regeneration techniques: experimental animal studies. Postepy Hig Med Dosw (Online) 62:282-288

27. Niemeyer P, Fechner K, Milz S, Richter W, Suedkamp NP, Mehlhorn AT, Pearce S, Kasten P (2010) Comparison of mesenchymal stem cells from bone marrow and adipose tissue for bone regeneration in a critical size defect of the sheep tibia and the influence of platelet-rich plasma. Biomaterials 31(13):3572-3579

28. Bi L, Cheng W, Fan H, Pei G (2010) Reconstruction of goat tibial defects using an injectable tricalcium phosphate/chitosan in combination with autologous platelet-rich plasma. Biomaterials 31(12): 3201-3211

29. Kon E, Filardo G, Delcogliano M, Fini M, Salamanna F, Giavaresi G, Martin I, Marcacci M (2010) Platelet autologous growth factors decrease the osteochondral regeneration capability of a collagenhydroxyapatite scaffold in a sheep model. BMC Musculoskelet Disord 11:220

30. Kanthan SR, Kavitha G, Addi S, Choon DS, Kamarul T (2011) Platelet-rich plasma (PRP) enhances bone healing in non-united critical-sized defects: a preliminary study involving rabbit models. Injury 42(8):782-789

31. Zhang YD, Wang G, Sun Y, Zhang CQ (2011) Combination of platelet-rich plasma with degradable bioactive borate glass for segmental bone defect repair. Acta Orthop Belg 77(1):110-115

32. Parizi AM, Oryan A, Shafiei-Sarvestani Z, Bigham AS (2012) Human platelet rich plasma plus Persian Gulf coral effects on experimental bone healing in rabbit model: radiological, histological, macroscopical and biomechanical evaluation. J Mater Sci: Mater Med 23(2):473-483

33. Oryan A, Meimandi Parizi A, Shafiei-Sarvestani Z, Bigham AS (2012) Effects of combined hydroxyapatite and human platelet rich plasma on bone healing in rabbit model: radiological, macroscopical, hidtopathological and biomechanical evaluation. Cell Tissue Bank 13(4):639-651

34. Kasten P, Beverungen M, Lorenz H, Wieland J, Fehr M, Geiger F (2012) Comparison of platelet-rich plasma and VEGF-transfected mesenchymal stem cells on vascularization and bone formation in a critical-size bone defect. Cells Tissues Organs 196(6):523-533

35. Kim YH, Furuya H, Tabata Y (2014) Enhancement of bone regeneration by dual release of a macrophage recruitment agent and platelet-rich plasma from gelatin hydrogels. Biomaterials 35(1): 214-224

36. Filardo G, Kon E, Tampieri A, Cabezas-Rodríguez R, Di Martino A, Fini M, Giavaresi G, Lelli M, Martínez-Fernández J, Martini L, Ramírez-Rico J, Salamanna F, Sandri M, Sprio S, Marcacci M (2014) New bio-ceramization processes applied to vegetable hierarchical structures for bone regeneration: an experimental model in sheep. Tissue Eng Part A 20(3-4):763-773
37. Zhong D, Wang CG, Yin K, Liao Q, Zhou X, Liu AS, Kong LY (2014) In vivo ossification of a scaffold combining $\beta$-tricalcium phosphate and platelet-rich plasma. Exp Ther Med 8(5):1381-1388

38. Chen H, Ji XR, Zhang Q, Tian XZ, Zhang BX, Tang PF (2016) Effects of calcium sulfate combined with platelet-rich plasma on restoration of long bone defect in rabbits. Chin Med J (Engl) 129(5):557-561

39. Dallari D, Fini M, Stagni C, Torricelli P, Nicoli Aldini N, Giavaresi G, Cenni E, Baldini N, Cenacchi A, Bassi A, Giardino R, Fornasari PM, Giunti A (2006) In vivo study on the healing of bone defects treated with bone marrow stromal cells, platelet-rich plasma, and freeze-dried bone allografts, alone and in combination. J Orthop Res 24(5):877-888

40. Kroese-Deutman HC, Vehof JW, Spauwen PH, Stoelinga PJ, Jansen JA (2008) Orthotopic bone formation in titanium fiber mesh loaded with platelet-rich plasma and placed in segmental defects. Int J Oral Maxillofac Surg 37(6):542-549

41. Molina-Miñano F, López-Jornet P, Camacho- Alonso F, VicenteOrtega V (2009) Plasma rich in growth factors and bone formation: a radiological and histomorphometric study in New Zealand rabbits. Braz Oral Res 23(3):275-280

42. Hakimi M, Jungbluth P, Sager M, Betsch M, Herten M, Becker J, Windolf J, Wild M (2010) Combined use of platelet-rich plasma and autologous bone grafts in the treatment of long bone defects in mini-pigs. Injury 41(7):717-723

43. Nather A, Wong KL, David V, Pereira BP (2012) Allografts with autogenous platelet-rich plasma for tibial defect reconstruction: a rabbit study. J Orthop Surg (Hong Kong) 20(3):375-380

44. Kurikchy MQ, Al-Rawi NH, Ayoub RS, Mohammed SS (2013) Histological evaluation of bone healing using organic bovine bone in combination with platelet-rich plasma (an experimental study on rabbits). Clin Oral Investig 17(3):897-904

45. Zhang ZY, Huang AW, Fan JJ, Wei K, Jin D, Chen B, Li D, Bi L, Wang J, Pei G (2013) The potential use of allogeneic platelet-rich plasma for large bone defect treatment: immunogenicity and defect healing efficacy. Cell Transplant 22(1):175-187

46. Schneppendahl J, Jungbluth P, Lögters TT, Sager M, Wild M, Hakimi M, Windolf J, Grassmann JP (2015) Treatment of a diaphyseal long-bone defect with autologous bone grafts and platelet-rich plasma in a rabbit model. Vet Comp Orthop Traumatol 28(3):164171

47. Park HC, Kim SG, Oh JS, You JS, Kim JS, Lim SC, Jeong MA, Kim JS, Jung C, Kwon YS, Ji H (2016) Early bone formation at a femur defect using CGF and PRF grafts in adult dogs: a comparative study. Implant Dent 25(3):387-393

48. Rabillard M, Grand JG, Dalibert E, Fellah B, Gauthier O, Niebauer GW (2009) Effects of autologous platelet rich plasma gel and calcium phosphate biomaterials on bone healing in an ulnar ostectomy model in dogs. Vet Comp Orthop Traumatol 22(6):460-466

49. Jungbluth P, Wild M, Grassmann JP, Ar E, Sager M, Herten M, Jäger M, Becker J, Windolf J, Hakimi M (2010) Platelet-rich plasma on calcium phosphate granules promotes metaphyseal bone healing in mini-pigs. J Orthop Res 28(11):1448-1455

50. Batista MA, Leivas TP, Rodrigues CJ, Arenas GC, Belitardo DR, Guarniero R (2011) Comparison between the effects of platelet-rich plasma and bone marrow concentrate on defect consolidation in the rabbit tibia. Clinics (Sao Paulo) 66(10):1787-1792

51. Bölükbașı N, Yeniyol S, Tekkesin MS, Altunatmaz K (2013) The use of platelet-rich fibrin in combination with biphasic calcium phosphate in the treatment of bone defects: a histologic and histomorphometric study. Curr Ther Res Clin Exp 75:15-21

52. Hakimi M, Grassmann JP, Betsch M, Schneppendahl J, Gehrmann S, Hakimi AR, Kröpil P, Sager M, Herten M, Wild M, Windolf J, Jungbluth P (2014) The composite of bone marrow concentrate and PRP as an alternative to autologous bone grafting. PLoS One 20;9(6):e100143 
53. Yilmaz D, Dogan N, Ozkan A, Sencimen M, Ora BE, Mutlu I (2014) Effect of platelet rich fibrin and beta tricalcium phosphate on bone healing. A histological study in pigs. Acta Cir Bras 29(1): 59-65

54. Malhotra R, Kumar V, Garg B, Singh R, Jain V, Coshic P, Chatterjee K (2015) Role of autologous platelet-rich plasma in treatment of long-bone nonunions: a prospective study. Musculoskelet Surg 99(3):243-248

55. Qi Y, Niu L, Zhao T, Shi Z, Di T, Feng G, Li J, Huang Z (2015) Combining mesenchymal stem cell sheets with platelet-rich plasma gel/calcium phosphate particles: a novel strategy to promote bone regeneration. Stem Cell Res Ther 6:256

56. Emilov-Velev K, Clemente-de-Arriba C, Alobera-García MÁ, Moreno-Sansalvador EM, Campo-Loarte J (2015) Bone regeneration in experimental animals using calcium phosphate cement combined with platelet growth factors and human growth hormone. Rev Esp Cir Ortop Traumatol 59(3):200-210

57. Simman R, Hoffmann A, Bohinc RJ, Peterson WC, Russ AJ (2008) Role of platelet-rich plasma in acceleration of bone fracture healing. Ann Plast Surg 61(3):337-344

58. Gumieiro EH, Abrahão M, Jahn RS, Segretto H, Alves MT, Nannmark U, Granström G, Dib LL (2010) Platelet-rich plasma in bone repair of irradiated tibiae of Wistar rats. Acta Cirurgica Brasileira 25(3):257-263

59. Souza TF, Andrade AL, Ferreira GT, Sakamoto SS, Albuquerque VB, Bonfim SR, Luvizotto MC, Louzada MJ (2012) Healing and expression of growth factors (TGF- $\beta$ and PDGF) in canine radial ostectomy gap containing platelet-rich plasma. Vet Comp Orthop Traumatol 25(6):445-452

60. Chen L, Yang X, Huang G, Song D, Ye XS, Xu H, Li W (2013) Platelet-rich plasma promotes healing of osteoporotic fractures. Orthopedics 36(6):e687-e694

61. Neves PC, Abib Sde C, Neves RF, Pircchio O, Saad KR, Saad PF, Simões RS, Moreira MB, Laurino CF (2013) Effect of hyperbaric oxygen therapy combined with autologous platelet concentrate applied in rabbit fibula fraction healing. Clin (Sao Paulo) 68(9):12391246

62. Hernandez-Fernandez A, Vélez R, Soldado F, Saenz-Rios JC, Barber I, Aguirre-Canyadell M (2013) Effect of administration of platelet-rich plasma in early phases of distraction osteogenesis: an experimental study in an ovine femur model. Injury 44(7):901-907

63. Guzel Y, Karalezli N, Bilge O, Kacira BK, Esen H, Karadag H, Toker S, Göncü RG, Doral MN (2015) The biomechanical and histological effects of platelet-rich plasma on fracture healing. Knee Surg Sports Traumatol Arthrosc 23(5):1378-1383

64. Rodriguez-Collazo ER, Urso ML (2015) Combined use of the Ilizarov method, concentrated bone marrow aspirate (cBMA), and platelet-rich plasma (PRP) to expedite healing of bimalleolar fractures. Strateg Trauma Limb Reconstr 10(3):161-166

65. Dallari D, Savarino L, Stagni C, Cenni E, Cenacchi A, Fornasari PM, Albisinni U, Rimondi E, Baldini N, Giunti A (2007) Enhanced tibial osteotomy healing with use of bone grafts supplemented with platelet gel or platelet gel and bone marrow stromal cells. J Bone Joint Surg Am 89(11):2413-2420

66. Peerbooms JC, Colaris JW, Hakkert AA, Van Appeldorn M, Bruijn DJ, Den Oudsten BL, Gosens T (2012) No positive bone healing after using platelet rich plasma in a skeletal defect. An observational prospective cohort study. Int Orthop Oct 36(10):2113-2119

67. Lee DH, Ryu KJ, Kim JW, Kang KC, Choi YR (2014) Bone marrow aspirate concentrate and platelet-rich plasma enhanced bone healing in distraction osteogenesis of the tibia. Clin Orthop Relat Res 472(12):3789-3797

68. Samy AM (2016) The role of platelet rich plasma in management of fracture neck femur: new insights. Int Orthop 40(5):1019-1024

69. Xavier GL, Achten J, Parsons NR, Costa ML (2013) Platelet-rich therapy in the treatment of patients with hip fractures: a single centre, parallel group, participant-blinded, randomised controlled trial. BMJ Open 3(6). doi:10.1136/bmjopen-2013-002583

70. Wei LC, Lei GH, Sheng PY, Gao SG, Xu M, Jiang W, Song Y, Luo W (2012) Efficacy of platelet-rich plasma combined with allograft bone in the management of displaced intra-articular calcaneal fractures: a prospective cohort study. Orthop Res 30(10):1570-1576

71. Liebergall M, Schroeder J, Mosheiff R, Gazit Z, Yoram Z, Rasooly L, Daskal A, Khoury A, Weil Y, Beyth S (2013) Stem cell-based therapy for prevention of delayed fracture union: a randomized and prospective preliminary study. Mol Ther 21(8):1631-1638

72. Namazi H, Mehbudi A (2016) Investigating the effect of intraarticular PRP injection on pain and function improvement in patients with distal radius fracture. Orthop Traumatol Surg Res 102(1):47-52

73. Calori GM, Tagliabue L, Gala L, d'Imporzano M, Peretti G, Albisetti W (2008) Application of rhBMP-7 and platelet-rich plas$\mathrm{ma}$ in the treatment of long bone non-unions: a prospective randomised clinical study on 120 patients. Injury 39(12):13911402

74. Calori GM, D'Avino M, Tagliabue L, Albisetti W, d'Imporzano M, Peretti G (2006) An ongoing research for evaluation of treatment with BMPs or AGFs in long bone non-union: protocol description and preliminary results. Injury 37(Suppl 3):S43-S50

75. Tarallo L, Mugnai R, Adani R, Catani F (2012) Treatment of the ulna non-unions using dynamic compression plate fixation, iliac bone grafting and autologous platelet concentrate. Eur J Orthop Surg Traumatol 22(8):681-687. doi:10.1007/s00590-011-0902-y

76. Mariconda M, Cozzolino F, Cozzolino A, D'Agostino E, Bove A, Milano C (2008) Platelet gel supplementation in long bone nonunions treated by external fixation. J Orthop Trauma 22(5):342-345

77. Say F, Türkeli E, Bülbül M (2014) Is platelet-rich plasma injection an effective choice in cases of non-union? Acta Chir Orthop Traumatol Cech 81(5):340-345

78. Malhotra R, Kumar V, Garg B, Singh R, Jain V, Coshic P, Chatterjee K (2015) Role of autologous platelet-rich plasma in treatment of long-bone nonunions: a prospective study. Musculoskelet Surg 99(3):243-248

79. Gołos J, Waliński T, Piekarczyk P, Kwiatkowski K (2014) Results of the use of platelet rich plasma in the treatment of delayed union of long bones.Ortop. Traumatol Rehabil 16(4):397-406

80. Galasso O, Mariconda M, Romano G, Capuano N, Romano L, Iannò B, Milano C (2008) Expandable intramedullary nailing and platelet rich plasma to treat long bone non-unions. J Orthop Traumatol 9(3):129-134

81. Sanchez M, Anitua E, Cugat R, Azofra J, Guadilla J, Seijas R, Andia I (2009) Nonunions treated with autologous preparation rich in growth factors. J Orthop Trauma 23(1):52-59

82. Bielecki T, Gazdzik TS, Szczepanski T (2008) Benefit of percutaneous injection of autologous platelet-leukocyte-rich gel in patients with delayed union and nonunion. Eur Surg Res 40(3):289-296

83. Chiang CC, Su CY, Huang CK, Chen WM, Chen TH, Tzeng YH (2007) Early experience and results of bone graft enriched with autologous platelet gel for recalcitrant nonunions of lower extremity. J Trauma 63(3):655-661

84. Andriolo L, Di Matteo B, Kon E, Filardo G, Venieri G, Marcacci M (2015) PRP Augmentation for ACL Reconstruction. Biomed Res Int 2015:371746

85. Filardo G, Di Matteo B, Kon E, Merli G, Marcacci M (2016) Platelet-rich plasma in tendon-related disorders: results and indications. Knee Surg Sports Traumatol Arthrosc. doi:10.1007/s00167016-4261-4

86. Marmotti A, Rossi R, Castoldi F, Roveda E, Michielon G, Peretti GM (2015) PRP and articular cartilage: a clinical update. Biomed Res Int 2015:542502

87. Reichert JC, Saifzadeh S, Wullschleger ME, Epari DR, Schütz MA, Duda GN, Schell H, van Griensven M, Redl H, Hutmacher DW 
(2009) The challenge of establishing preclinical models for segmental bone defect research. Biomaterials 30(12):2149-2163

88. Gianakos A, Zambrana L, Savage-Elliott I, Lane JM, Kennedy JG (2015) Platelet-rich plasma in the animal long-bone model: an analysis of basic science evidence. Orthopedics 38(12):e1079-e1090

89. Tschon M, Fini M, Giardino R, Filardo G, Dallari D, Torricelli P, Martini L, Giavaresi G, Kon E, Maltarello MC, Nicolini A, Carpi A (2011) Lights and shadows concerning platelet products for musculoskeletal regeneration. Front Biosci (Elite Ed) 1(3):96-107

90. Weibrich G, Hansen T, Kleis W, Buch R, Hitzler WE (2004) Effect of platelet concentration in platelet-rich plasma on peri-implant bone regeneration. Bone 34(4):665-671

91. Roffi A, Filardo G, Assirelli E, Cavallo C, Cenacchi A, Facchini A, Grigolo B, Kon E, Mariani E, Pratelli L, Pulsatelli L, Marcacci M
(2014) Does platelet-rich plasma freeze-thawing influence growth factor release and their effects on chondrocytes and synoviocytes? Biomed Res Int 2014:692913

92. Cavallo C, Roffi A, Grigolo B, Mariani E, Pratelli L, Merli G, Kon E, Marcacci M, Filardo G (2016) Platelet-rich plasma: the choice of activation method affects the release of bioactive molecules. Biomed Res Int 2016:6591717

93. Dohan Ehrenfest DM, Bielecki T, Jimbo R, Barbé G, Del Corso M, Inchingolo F, Sammartino G (2012) Do the fibrin architecture and leukocyte content influence the growth factor release of platelet concentrates? An evidence-based answer comparing a pure platelet-rich plasma (P-PRP) gel and a leukocyte- and platelet-rich fibrin (L-PRF). Curr Pharm Biotechnol 13(7):1145-1152 